\title{
Correspondence
}

\section{Guidelines to Staff on Confidentiality}

Dear Sir,

Dr Baldwin, Dr Leff and Professor Wing, of the Social and Community Psychiatry Section of the Royal College of Psychiatrists, have stated (British Journal of Psychiatry (1976) 128, 417-27) that the risk of leaks of confidentiality were perhaps greater from information kept inside the hospital than from information sent to outside computers. Our hospital's Records and Confidentiality Sub-Committee has already tried to improve the security of information outside our hospitals (Bulletin, March 1979, p 47); it is now trying to improve the security of information within them.

While realizing that each consultant must make up his own mind on any action concerning the imparting of confidential information, we have felt that the various clerical workers in the hospital are often unsure whether or not it is proper to give information on request and that we should give them some guidelines. After much discussion and consultation, we have drafted such guidelines for clerical staff, and later will offer them to our nursing colleagues as a basis for any guidelines they may wish to produce for nurses.

Since it took much effort to produce these guidelines, we feel that psychiatrists in other hospitals who may also be trying to tighten up their local security of confidential information might be glad to see them and possibly use them as a basis for their own. We are not sure we have got them right and would welcome criticism and suggestions. We feel that this subject, though tedious and dull, is an important one which should be discussed and we therefore append a summary of our guidelines.

Knowle Hospital

ZAIDA M. HALL

Fareham

Hants PO17 5NA

\section{Summary of Guidelines for Clerical Stafi*}

Members of staff in possession of medical records must safeguard them in order to maintain confidentiality of information about patients.

\section{A. Release of Information about Patients}

1. Authority for release of information

Authority to release medical information must always come from either the consultant in charge of the patient, a member of his medical team, the Data Custodian or his deputy. Since admission implies a psychiatric diagnosis, a telephone reply should in the

- These guidelines are not intended for the telephonist who passes an enquiry on to the relevant ward or department, nor for nurses who deal with most enquiries from relatives about patients actually in the ward or day hospital. first instance give no indication that the alleged patient is actually a patient in the hospital or ward, and if the identity of a caller is in doubt, the recipient should ask for the caller's number and ring back after checking. Whenever possible information should be requested in writing. Information should not be given even to the police, the court or solicitors without the consultant's permission, except in certain situations (see Para 2).

Telephone requests from general practitioners should be referred directly to the consultant or his team.

2. Situations in : hhich information can be given without the permission of the consultant

(i) Enquiries concerning National Insurance and Supplementary Benefit from the DHSS (and occasionally, with the patient's consent, his employer) arising from a medical certificate for sickness benefit signed by the patient and sent by him to the DHSS, sometimes via his employer. (The patient's permission may be assumed to be implicit in his signature on the form, and the maintenance of confidentiali,j by his employer or the DHSS must be assumed.)

(ii) Information concerning a patient's property requested by the Court of Protection or a person appointed as Receiver.

(iii) Information requested by a Coroner or his deputy (but not by the Coroner's Officer, who is a police officer) should be given at once (though legal compulsion to give it occurs strictly only at the Inquest).

(iv) Where there has been a serious assault by a patient while on hospital property, or serious thef, or serious damage to hospital property, information about a patient may have to be released to the District Administrator or to the police, but only with the authority of the Sector or Hospital Administrator who will, wherever possible, discuss any proposed disclosures with the consultant concerned, and will, where appropriate, obtain the patient's consent to any disclosure.

(v) In addition, statutory regulations demanding automatic release of specific information about patients by doctors apply in cases of notification of infectious diseases, drug abuse forms for the DHSS, certification of cause of death and registration of death.

\section{B. Safe-Keeping of Case-Notes}

\section{Access to case-notes}

Members of the specific multidisciplinary team dealing with a patient in the ward or day hospital, or involved clinically with an out-patient, may need to 